Full length article

\title{
Thin-layer chromatography coupled with high performance liquid chromatography for determining tetrabromobisphenol A/S and their derivatives in soils
}

\author{
Aifeng Liu ${ }^{a}$, Zhaoshuang Shen ${ }^{a}$, Yong Tian ${ }^{a}$, Rongguang Shi ${ }^{b}$, Yi Liu ${ }^{c}$, Zongshan Zhao ${ }^{a}, *$ \\ Mo Xian ${ }^{\text {a }}$ \\ a CAS Key Laboratory of Biobased Materials, Qingdao Institute of Bioenergy and Bioprocess Technology, Chinese Academy of Sciences, Qingdao, 266101, PR \\ China \\ b Agro-Environmental Protection Institute, Ministry of Agriculture, Tianjin, 300191, PR China \\ c School of Chemistry and Chemical Engineering, Yantai University, Yantai, 264005, PR China
}

\section{A R T I C L E I N F O}

\section{Article history:}

Received 28 June 2017

Received in revised form 18 October 2017

Accepted 19 October 2017

Available online 20 October 2017

\section{Keywords:}

Thin-layer chromatography

Tetrabromobisphenol A/S

Derivatives

Soil sample

High performance liquid chromatography

\begin{abstract}
A B S T R A C T
As brominated flame retardants (BFRs), tetrabromobisphenol A/S (TBBPA/S) and their derivatives have raised wide concerns owing to their widely usage, distributions and adverse effects on human health, thus monitoring these BFRs was urgently needed. In this study, a rapid and cost-effective method based on thin-layer chromatography (TLC) sample pre-treatment coupled with high performance liquid chromatography-diode array detector (HPLC-DAD) (UV=214 nm) was developed for determining TBBPA/S and their derivatives in soils, including TBBPA, TBBPA bis(allyl ether) (TBBPABAE), TBBPA bis(2,3-dibromopropyl ether) (TBBPA-BDBPE), TBBPS bis(allyl ether) (TBBPS-BAE) and TBBPS bis(2,3-dibromopropyl ether) (TBBPS-BDBPE). The method detection limits (MDLs) and the method quantification limits (MQLs) for these BFRs ranged from 0.023 to $0.087 \mu \mathrm{g} \mathrm{g}^{-1} \mathrm{dw}$ and $0.076-0.29 \mu \mathrm{gg}^{-1} \mathrm{dw}_{\text {, }}$ respectively. The recoveries were $41-108 \%$ and both RSD of repeatability and intermediate precision were less than $11 \%$. The developed method presented good performance for analyzing natural soil samples collected from BFRs industrial park, suggesting its great application potential for monitoring environmental TBBPA/S and their derivatives.
\end{abstract}

(C) 2017 Elsevier B.V. All rights reserved.

\section{Introduction}

Tetrabromobisphenol A (TBBPA), tetrabromobisphenol $\mathrm{S}$ (TBBPS) and their derivatives are the most widely used brominated flame retardants (BFRs), accounting for $60 \%$ of total BFRs market $[1,2]$. As additive products in plastics, ABS resins, etc., TBBPA/S and their derivatives are easily released to the environment during their production and usage processes and then cause potentially adverse environment and health risks [1-3]. Their universality in various environmental media have been revealed, such as TBBPA bis(2,3-dibromopropyl ether) (TBBPA-BDBPE) in the atmosphere [4] as well as in indoor dust [5], and TBBPA-BDBPE, TBBPA bis(allyl ether) (TBBPA-BAE) and TBBPS bis(2,3-dibromopropyl ether) (TBBPS-BDBPE) in herring gull eggs [6]. The toxicological effects related to these BFRs, such as endocrine disruption effects,

\footnotetext{
* Corresponding author.

E-mail address: zhaozs@qibebt.ac.cn (Z.Zhao).
}

neurotoxicity and reproductive development toxicity, indicate their potential threats to organisms [7]. Therefore, monitoring these compounds by using a convenient and effective method has become a critical issue for studying their environmental behaviors, fate and toxicities [7-10].

Gas chromatography-mass spectrometry (GC-MS) [1,2,11] and high performance liquid chromatography-mass spectrometry (HPLC-MS) [6,11-13] are the most common proposed methods for determining TBBPA/S and their derivatives. Due to the thermal decomposition for directly analyzing TBBPA and derivatives, GC-MS methods are always not preferred for determining TBBPA/S and their derivatives [14]. For HPLC-MS methods, a variety of ion sources have been introduced to meet the analysis demand of complex samples, such as electrospray ionizationmass spectrometry (ESI-MS) [12], atmospheric pressure chemical ionization-mass spectrometry (APCI-MS) [13] and atmospheric pressure photoionization-mass spectrometry (APPI-MS) $[11,15]$. But their popularization for monitoring these BFRs is often limited partly owing to ionization difficulties resulted from the prop- 
erties of the instruments and compounds. For example, the ESI source could not produce any precursor ions for TBBPA-BAE and TBBPA-BDBPE under full-scan optimization $[10,16]$, the APCI source often leads to poor sensitivity [16], the unpopular APPI source needs an additional and appropriate dopant agent for ionization $[11,17]$ and the extractive electrospray ionization-mass spectrometry (EESI-MS) needs a series of hard modifications of equipment [12].

Beyond that, cumbersome sample pretreatments for TBBPA/S and their derivatives are inevitable when using the methods based on MS techniques. Overall, these pretreatments, such as accelerated solvent extraction (ASE) [18], soxhlet extraction [14], liquid-liquid extraction [12,17], solid phase extraction (SPE) [11], gel permeation chromatography (GPC) [19], etc., are timeconsuming, solvent-consuming and costly. Additionally, extra effort-consuming derivation is necessary for analyzing TBBPA by GC-MS because of its thermolability [11]. The controversially extreme conditions including the usage of concentrated sulfuric acid have also been introduced to eliminate the matrix interference, though they can lead to the positive decomposition of TBBPA under strongly oxidized condition [20]. Therefore, developing a rapid and cost-effective method for monitoring TBBPA/S and their derivatives is still urgently needed.

HPLC-DAD, a practical method for determining polar compounds, has also been proposed as a supplementary method for determining TBBPA/S and their derivatives [21-23], such as TBBPABDBPE and TBBPA-BAE in soil [9] and biological samples [7,23,24], TBBPA in food [25], water [26] and biological samples [21,22]. But it often suffers from the interfering substances due to its identification mainly depending on the retention time of target compounds [9]. Elimination of interferences is one of the most important improvements for HPLC-DAD methods. Thin-layer chromatography (TLC) technique, a useful separation technique in pharmaceutical and biomedical field [27-34], possesses higher sample throughput, shorter analysis time and less extract and clean-up procedure than conventional pretreatment techniques [35]. In this study, a novel method coupled HPLC-DAD with TLC technique has been developed for determining TBBPA, TBBPA-BAE, TBBPA-BDBPE, TBBPS-BAE and TBBPS-BDBPE in soil samples. The method performances for environmental samples have been evaluated by analyzing these five TBBPA/S derivatives in natural soil samples.

\section{Experimental}

\subsection{Chemicals and materials}

Acetone, methanol, dichloromethane (DCM), n-hexane, ethyl acetate and acetonitrile, purchased from Merck (Darmstadt, Germany) and Fisher Scientific (Trinidad, UK), are HPLC or pesticide grade. Formic acid is obtained from Dikma technologies (USA). TBBPA, TBBPA-BAE, TBBPA-BDBPE, TBBPS-BAE and TBBPS-BDBPE are from Sigma-Aldrich (Steinheim, Germany). Ultrapure water is obtained from a Milli-Q advantage A10 system.

TLC plate $(7.5 \mathrm{~cm} \times 2.5 \mathrm{~cm})$ is from Qingdao Haiyang Chemical Co., Ltd in China. The glass plates are precoated with silica gel $\mathrm{GF}_{254}$ and the coating thickness is $0.20-0.25 \mathrm{~mm}$. Glass capillary $(5 \mu \mathrm{L})$ is purchased from Hirschmann Laborgerate.

\subsection{Soil sample extraction}

Soil samples were collected from a large BFRs industrial park located in Weifang, Shandong Province, China. The soil samples were air dried, grinded, sieved (100 mesh) and stored in refrigerator at $-20^{\circ} \mathrm{C}$ before analysis.

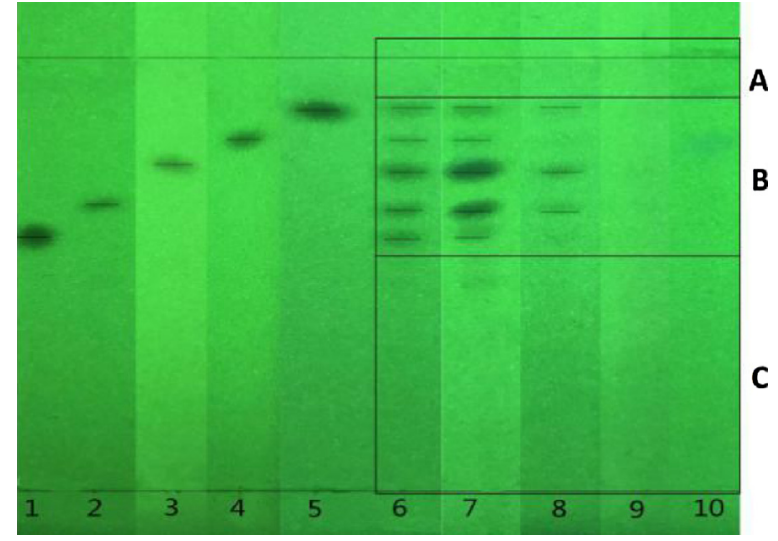

Fig. 1. TLC fingerprint profile of standards and soil samples at $254 \mathrm{~nm}$. 1, TBBPA, 2 , TBBPS-BDBPE, 3, TBBPS-BAE, 4, TBBPA-BDBPE, 5, TBBPA-BAE, 6, standard mixture $7,8,9$, the spiked soil sample solutions, 10 , the blank soil samples.

Soil samples $(1 \mathrm{~g})$, mixed with $5 \mathrm{~g}$ of anhydrous $\mathrm{Na}_{2} \mathrm{SO}_{4}$, were ultrasonically extracted with $15 \mathrm{~mL}$ of a mixture DCM: $n$-hexane $(1: 1, v / v)$ for $15 \mathrm{~min}$ after blending sufficiently. The extraction process was repeated twice, and the extracts were combined and concentrated using rotary evaporator. The residues were then solvent-exchanged to $0.1 \mathrm{~mL}$ of acetone before TLC sample pretreatment. For the recovery experiments, each sample was spiked with the standards, mixed sufficiently and kept overnight before extraction. The extraction process was followed the procedure described above.

\subsection{TLC separation}

TLC separation was performed on a TLC plate $(7.5 \mathrm{~cm} \times 2.5 \mathrm{~cm})$ precoated with silica gel $\mathrm{GF}_{254}$. Concentrated extracts from soil samples and standard solution $(20 \mu \mathrm{L})$ were applied on one plate ( $5 \mu \mathrm{L}$ of each for four equal sample points) as $7 \mathrm{~mm}$ bands, $7 \mathrm{~mm}$ from the bottom edge by $5 \mu \mathrm{L}$ of capillary. The plates were developed with $0.5 \mathrm{~mL}$ of $n$-hexane: ethyl acetate: DCM: formic acid $(30: 6: 1: 1, v / v)$ as the mobile phase (migration distance, $5 \mathrm{~cm}$ ) in a vitreous chamber at room temperature. After development and drying, visual detection of the plates was carried out at $254 \mathrm{~nm}$ in ZF-20C camera obscura ultraviolet analyzer. Referring to standards, the zones belong to TBBPA, TBBPA-BAE, TBBPA-BDBPE, TBBPSBAE, TBBPS-BDBPE (2.7-4.4 cm off the baseline) were then marked and scraped from the surface of the plate layer. Target compounds were extracted from the scraped layer by acetone $(20 \mathrm{~mL})$, solvent-changed to methanol $(500 \mu \mathrm{L})$ and further filtered through a $0.45 \mu \mathrm{m}$ Nylon Syringe filters for HPLC analysis.

\subsection{HPLC analysis}

HPLC (Waters 1250 series) equipped with a photodiode array detector and Chemstation software was used for the instrument analysis. Pretreated samples $(20 \mu \mathrm{L})$ were injected by automatic sampler, separated on an Agilent Zorbax ODS column $(5 \mu \mathrm{m}$, $150 \mathrm{~mm} \times 3 \mathrm{~mm}$ ) and detected by photodiode array detector (UV $214 \mathrm{~nm}$ ). The best separation was achieved at a flow rate of $600 \mu \mathrm{L} \mathrm{min}^{-1}$ with acetonitrile and water (containing $0.1 \%$ formic acid) as the mobile phase. The linear gradient started isocratic at $60 \%$ acetonitrile for $3 \mathrm{~min}$, then increased to $90 \%$ in $5 \mathrm{~min}$ and to $100 \%$ in another $8 \mathrm{~min}$ respectively. After remaining at $100 \%$ acetonitrile for $2 \mathrm{~min}$, the gradient returned to $60 \%$ acetonitrile in $2 \mathrm{~min}$ and kept for $3 \mathrm{~min}$. 

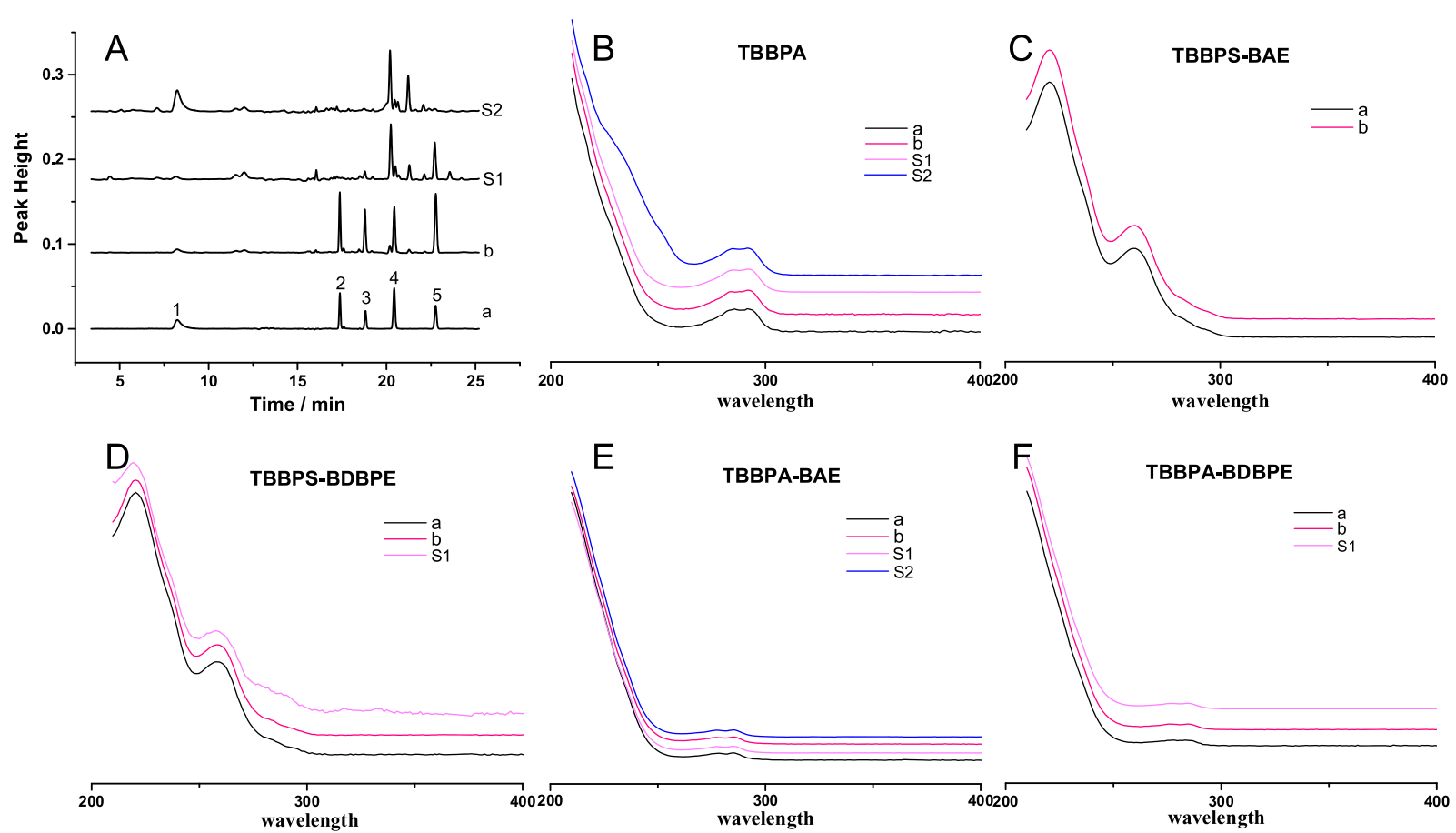

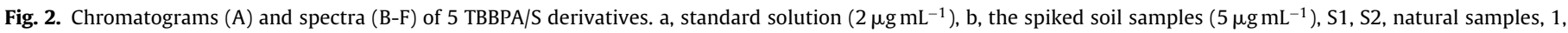
TBBPA, 2, TBBPS-BAE, 3, TBBPS-BDBPE, 4, TBBPA-BAE, 5, TBBPA-BDBPE.

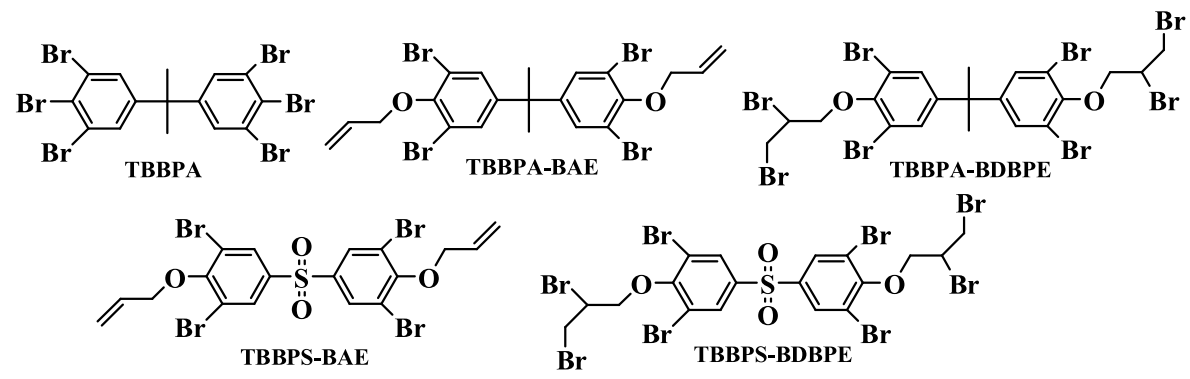

Fig. 3. Chemical structures of the studied compounds.

\subsection{Statistical analyses}

Statistical comparisons of several mean values were performed by using one-way analyses of variance (ANOVA), taking the appropriate condition as a single factor. When the ANOVA leads to significant results, least significant difference (LSD) test was performed to identify where the differences occur. Statistically significant difference was defined as $p<0.05$. The analyses were carried out by SPSS Data Editor (version 20.0). Waters Empower in the work station of Waters 1250 HPLC was used for peak purity tests of the analytes. A calculated purity angle less than purity threshold indicated a pure analyte peak.

\section{Results and discussion}

\subsection{Method optimization}

Standard solutions of the target compounds were used to optimize the developing solvents and applied volume for achieving good separation and narrow bands. Various combinations of the developing solvents, comprising those reported in the literature $(n-$ hexane: ethyl acetate $(5: 1, v / v))$ and fine-tuning ( $n$-hexane: ethyl acetate: DCM (30:6:1, v/v); $n$-hexane: ethyl acetate: formic acid (30:6:1, v/v); $n$-hexane: ethyl acetate: DCM: formic acid (30:6:1:1, $\mathrm{v} / \mathrm{v})$ ) $[30,36]$, were thoroughly tested. Better separation of analytes (fall into target zone, Fig. 1(B)) from co-extracted interferences (Fig. 1(A), (C)) and narrower bands of target zone were obtained with $n$-hexane: ethyl acetate: DCM: formic acid $(30: 6: 1: 1, v / v)$ as the developing solvents. The various applied volume of $2 \mu \mathrm{L}, 5 \mu \mathrm{L}$, $10 \mu \mathrm{L}$ and $20 \mu \mathrm{L}$ was evaluated to obtain narrow, distinct and regular bands and stable retention factor $\left(R_{f}\right)$ value that might decrease recovery on account of artificial operation. It tuned out that an application volume of less than $5 \mu \mathrm{L}$ showed perfect fingerprints.

Compared with conventional pretreatment techniques, TLC presented shorter analysis time, less solvent consumption, simpler clean-up procedure and lower cost, etc., than conventional pretreatment techniques in our study [35]. The solvent consumption and time consumption of TLC $(<30 \mathrm{~mL},<30 \mathrm{~min})$ was much less than GPC $(>200 \mathrm{~mL},>90 \mathrm{~min})$ [9]. The commercial silica gel plate selected was 10 times cheaper than SPE (e.g. LC-Si) cartridges [21,24]. The chromatographic process only covering physical adsorption and partition process can also effectively avoid the oxidation and degradation of these tested BFRs during pretreatment process. 
Table 1

Method performance results of the developed TLC-HPLC-DAD method for TBBPA/S derivatives.

\begin{tabular}{|c|c|c|c|c|c|c|}
\hline & $\begin{array}{l}\text { Spiked } \\
\text { concentration } \\
\left(\mu g^{-1}\right)\end{array}$ & ТВВРА & TBBPS-BAE & TBBPS-BDBPE & TBBPA-BAE & TBBPA-BDBPE \\
\hline Models & - & $\begin{array}{l}\mathrm{A}=-2.2 \times 10^{4} \\
+1.8 \times 10^{5} \mathrm{C}\end{array}$ & $\begin{array}{l}\mathrm{A}=3.8 \times 10^{4} \\
+1.2 \times 10^{5} \mathrm{C}\end{array}$ & $\begin{array}{l}A=7.7 \times 10^{3} \\
+7.7 \times 10^{4} C\end{array}$ & $\begin{array}{l}A=8.9 \times 10^{4} \\
+1.8 \times 10^{5} \mathrm{C}\end{array}$ & $\begin{array}{l}\mathrm{A}=1.4 \times 10^{4} \\
+1.2 \times 10^{5} \mathrm{C}\end{array}$ \\
\hline $\mathrm{r}$ & & 0.9999 & 0.9997 & 0.9999 & 0.9993 & 0.9999 \\
\hline Recovery (\%) & $\begin{array}{l}6.25 \\
12.5 \\
25 \\
50 \\
125\end{array}$ & $\begin{array}{l}53 \pm 1 \\
41 \pm 4 \\
61 \pm 3 \\
67 \pm 7 \\
76 \pm 2\end{array}$ & $\begin{array}{l}92 \pm 4 \\
90 \pm 1 \\
75 \pm 8 \\
87 \pm 2 \\
92 \pm 5\end{array}$ & $\begin{array}{l}100 \pm 5 \\
86 \pm 3 \\
95 \pm 3 \\
103 \pm 4 \\
97 \pm 3\end{array}$ & $\begin{array}{l}51 \pm 4 \\
73 \pm 2 \\
80 \pm 4 \\
86 \pm 1 \\
84 \pm 5\end{array}$ & $\begin{array}{l}105 \pm 2 \\
96 \pm 4 \\
101 \pm 5 \\
108 \pm 4 \\
105 \pm 4\end{array}$ \\
\hline Matrix effect (\%) & $\begin{array}{l}2 \mu \mathrm{g} \mathrm{mL}^{-1} \\
5 \mu \mathrm{gL}^{-1} \\
10 \mu \mathrm{g} \mathrm{mL}^{-1}\end{array}$ & $\begin{array}{l}-0.76 \\
-3.57 \\
-5.68\end{array}$ & $\begin{array}{l}4.66 \\
-1.39 \\
-3.70\end{array}$ & $\begin{array}{l}0.55 \\
-4.17 \\
0.22\end{array}$ & $\begin{array}{l}7.68 \\
8.44 \\
1.28\end{array}$ & $\begin{array}{l}8.10 \\
5.09 \\
2.68\end{array}$ \\
\hline $\begin{array}{l}\text { MDLs }\left(\mu g^{-1}\right) \\
\operatorname{MQLs}\left(\mu g^{-1}\right)\end{array}$ & & $\begin{array}{l}0.087 \\
0.29\end{array}$ & $\begin{array}{l}0.025 \\
0.081\end{array}$ & $\begin{array}{l}0.049 \\
0.16\end{array}$ & $\begin{array}{l}0.023 \\
0.076\end{array}$ & $\begin{array}{l}0.036 \\
0.12\end{array}$ \\
\hline $\begin{array}{l}\text { Intermediate precision } \\
\text { RSD (\%) }\end{array}$ & $\begin{array}{l}\text { Intraday } \\
\text { Interday }\end{array}$ & $\begin{array}{l}2.06 \\
2.14\end{array}$ & $\begin{array}{l}0.62 \\
0.59\end{array}$ & $\begin{array}{l}0.62 \\
1.56\end{array}$ & $\begin{array}{l}1.08 \\
0.99\end{array}$ & $\begin{array}{l}0.79 \\
1.84\end{array}$ \\
\hline
\end{tabular}

Under the optimized instrumental parameters, five target compounds could be baseline separated completely and quantified within 25 min (Fig. 2A). The identification of these compounds in the test solutions was verified by comparing the retention time $\left(t_{R}\right)$ and spectrum (Fig. 2) with the standard solutions from $8.24 \mathrm{~min}$ (TBBPA) to 22.76 min (TBBPA-BDBPE). Meanwhile, purity angles of the analytes were all less than purity thresholds, indicating peak purity of the analytes.

\subsection{Method performance}

Due to the probable degradation during the purification process in an open system [32], the stability of the target compounds (Fig. 3) in methanol at different storing temperature and on the plate were evaluated. The standard solutions $\left(10 \mu \mathrm{g} \mathrm{mL}^{-1}\right)$ were stored at $-20^{\circ} \mathrm{C}$ and $4{ }^{\circ} \mathrm{C}$ for two weeks, and then analyzed. Compared with the freshly prepared standards, the results showed that the solutions were stable below $4{ }^{\circ} \mathrm{C}$ in two weeks $(p>0.05)$. Besides, a standard solution ( $1.25 \mathrm{mg} \mathrm{mL}^{-1}$ ) was freshly prepared and applied on new plates. The plates were exposed to air and light for the intervals of $0,30,60$ and 120 min before development. Compared with the freshly prepared standards, the results showed that the development on the plate should be finished in $30 \mathrm{~min}$ $(p>0.05)$.

The specificity of the method was ascertained according to $R_{f}$ of fingerprints from the TLC plate images and the retention time $\left(t_{R}\right)$ of HPLC chromatogram. $R_{f}, t_{R}$, and spectra of the sample solutions were appropriately in agreement with that of standard solutions $\left(\mathrm{R}_{\mathrm{f}}, 0.54 \sim 0.88\right.$, Fig. $1 ; \mathrm{t}_{\mathrm{R}}, 8.24 \sim 22.76$, Fig. $\left.2 \mathrm{~A}\right)$. The range of linearity was from $0.1 \mu \mathrm{g} \mathrm{mL} L^{-1}$ to $100 \mu \mathrm{g} \cdot \mathrm{mL}^{-1}$, with the correlation coefficients ( $r$ ) higher than 0.9993 for all the five target compounds (Table 1).

The method detection limits (MDLs) and the method quantification limits (MQLs) were defined as the signal to noise $(\mathrm{S} / \mathrm{N}$ ) ratios of 3:1 and 10:1. The MDLs and MQLs for TBBPA/S and their derivatives ranged from 0.023 to $0.087 \mu \mathrm{gg}^{-1} \mathrm{dw}$ and from 0.076 to $0.29 \mu \mathrm{g} \mathrm{g}^{-1} \mathrm{dw}$, respectively (Table 1 ). The MDLs of TBBPA $\left(0.087 \mu \mathrm{gg}^{-1}\right)$ and TBBPA-BDBPE $\left(0.036 \mu \mathrm{gg}^{-1}\right)$ were comparable with that obtained using HPLC-DAD $\left(0.015 \mu \mathrm{g} \mathrm{g}^{-1}\right.$ of TBBPA [22], $0.006 \mu \mathrm{g} \mathrm{g}^{-1}$ of TBBPA-BDBPE [7] for biological samples).

Compared with some novel methods based on MS, the MDLs of TBBPA-BAE, TBBPA-BDBPE and TBBPS-BDBPE $(0.023,0.036$ and $\left.0.049 \mu \mathrm{g} \mathrm{g}^{-1}\right)$ in this study were higher, eg. the MDLs of TBBPABAE $\left(0.03 \mathrm{ng} \mathrm{g}^{-1}\right)$, TBBPA-BDBPE $\left(0.07 \mathrm{ng} \mathrm{g}^{-1}\right)$ and TBBPS-BDBPE
(1.28 $\mathrm{ng} \mathrm{g}^{-1}$ ) for herring gull eggs by LC-APPI-MS [11], the MDLs of TBBPA-BAE $\left(0.76 \mu \mathrm{g} \mathrm{L}^{-1}\right)$, TBBPS-BAE $\left(4.6 \mu \mathrm{g} \mathrm{L}^{-1}\right)$ for waters by EESI-MS $[12,17]$. The instrument sensitivity of HPLC-DAD is the bottle-neck for the developed method, but HPLC-DAD can embody the advantage in the instrument price and usability for regular monitoring. Meanwhile, in view of the shorter analysis time and less extract and clean-up procedure of TLC separation, the developed method is proposed to be a supplementary technique for determining TBBPA/S and their derivatives.

The accuracy of the proposed method was evaluated by spiking blank soil sample with the analytes at concentrations of $6.25,12.5$, 25,50 and $125 \mu^{-1} g^{-1}$ [32]. The recoveries were from $41 \%$ to $108 \%$ and RSD were all less than $11 \%$ (Table 1 ). The intermediate precision was also examined by injection of freshly prepared standard solutions $\left(5 \mu \mathrm{g} \mathrm{mL}^{-1}\right)$ in triplicate in one day and consecutive 3 days. The results of the intra- and inter-days precision were also shown in Table 1 and the RSD values ranged from $0.59 \%$ to $2.14 \%$. These results indicated the stability of the method can meet the demand for monitoring these BFRs in soil samples.

\subsection{Assessment of matrix effect}

Due to the potential target signal enhancement or suppression caused by interferences, the matrix effects have been evaluated to assess the accuracy of the method. The matrix effects of soil samples were calculated by using the following Eq. (1) and the results were shown in Table 1.

Matrix effect $=\frac{C_{s 2}-C_{s 1}}{C_{s 1}} \times 100 \%$

$C_{s 1}$ was the concentrations of standard solutions of the studied BFRs in methanol and $C_{s 2}$ was the measured concentrations of the extracted and pretreated solution from blank soil sample spiked with equal standard solutions, with the same amounts of BFRs to $C_{s 1}$. The matrix effect experiments are composed of three groups of samples and the concentrations of the standard solutions are 2, 5 and $10 \mu \mathrm{g} \mathrm{mL}^{-1}$. The results were shown in Table 1 and the matrix effects ranged from $-5.68 \%$ to $8.44 \%$, indicating that the matrix effects of soil samples could be ignored.

\subsection{Application in natural soil samples}

The performance of the developed TLC-HPLC-DAD method for monitoring environmental TBBPA/S and their derivatives were 
evaluated by using two natural soil samples obtained from a large BFRs industrial park located in Weifang City, Shandong Province. Four compounds including TBBPA $\left(2.0 \mu \mathrm{g} \mathrm{g}^{-1}\right)$, TBBPSBDBPE $\left(3.1 \mu \mathrm{gg}^{-1}\right)$, TBBPA-BAE $\left(2.2 \mu \mathrm{gg}^{-1}\right)$ and TBBPA-BDBPE $\left(12.3 \mu \mathrm{g} \mathrm{g}^{-1}\right)$ were detected in soil sample of S1 and two compounds including TBBPA $\left(24.6 \mu \mathrm{g} \mathrm{g}^{-1}\right)$ and TBBPA-BAE $\left(2.1 \mu \mathrm{g} \mathrm{g}^{-1}\right)$ were found in soil sample of S2 (Fig. 2). Comparison of the chromatograms and spectra of the analytes with standards (Fig. 2) and determination of the peaks purity indicated that the chromatographic peaks were pure, and further confirmed the real presence of these analytes in soil samples. The developed method can indeed meet the demand for monitoring these BFRs in the ambient area of BFRs plant.

\section{Conclusion}

In this study, a novel method based on TLC technique coupled with HPLC-DAD has been developed for analysis of five TBBPA/S and their derivatives in soil samples. The proposed method presented simple, time-saving and solvent-saving pretreatment procedures, satisfactory precision, acceptable limits of detection, good recoveries and ignorable matrix effects for monitoring these compounds. Comparing with previous methods, TLC can dramatically simplify the sample pretreatment process without significant matrix effects. Using the developed method, high contents of TBBPA/S and their derivatives in soil samples were detected, indicating that this method should be an important supplementary technique for monitoring these compounds in the environment.

\section{Acknowledgements}

This work was supported by the National Natural Science Foundation of China (21707148, 21407086 and 21402192), the State Key Laboratory of Environmental Chemistry and Ecotoxicology, Research Center for Eco-Environmental Sciences, Chinese Academy of Sciences (No. KF2016-12), the China Postdoctoral Science Foundation (2016M602210).

\section{References}

[1] A. Covaci, S. Harrad, M.A.E. Abdallah, N. Ali, R.J. Law, D. Herzke, C.A.d. Wit, Novel brominated flame retardants: a review of their analysis, environmental fate and behaviour, Environ. Int. 37 (2011) 532-556

[2] A. Covaci, S. Voorspoels, M. Abou-Elwafa Abdallah, T. Geens, S. Harrad, R.J. Law, Analytical and environmental aspects of the flame retardant tetrabromobisphenol-A and its derivatives, J. Chromatogr. A 1216 (2009) 346-363.

[3] R.A. Hites, Polybrominated diphenyl ethers in the environment and in people: a meta-analysis of concentrations, Environ. Sci. Technol. 38 (2004) 945-956.

[4] L. Liu, M. Venier, A. Salamova, R.A. Hites, A novel flame retardant in the great lakes atmosphere: 3,3 ',5,5 '-Tetrabromobisphenol a bis(2,3-dibromopropyl) ether, Environ sci. Technol. 3 (2016) 194-199.

[5] N. Ali, S. Harrad, E. Goosey, H. Neels, A. Covaci, Novel brominated flame retardants in Belgian and UK indoor dust: implications for human exposure, Chemosphere 83 (2011) 1360-1365.

[6] L.T. Gauthier, D. Potter, C.E. Hebert, R.J. Letcher, Temporal trends and spatial distribution of non-polybrominated diphenyl ether flame retardants in the eggs of colonial populations of great lakes herring gulls, Environ. Sci. Technol. 43 (2008) 312-317.

[7] A. Liu, G. Qu, M. Yu, Y. Liu, J. Shi, G. Jiang, Tetrabromobisphenol-A/S and nine novel analogs in biological samples from the chinese bohai sea: implications for trophic transfer, Environ. Sci. Technol. 50 (2016) 4203-4211.

[8] L. Liu, A. Liu, Q. Zhang, J. Shi, B. He, Z. Yun, G. Jiang, Determination of tetrabromobisphenol-A/S and their main derivatives in water samples by high performance liquid chromatography coupled with inductively coupled plasma tandem mass spectrometry, J. Chromatogr. A 1497 (2017) 81-86.

[9] A. Liu, J. Shi, G. Qu, L. Hu, Q. Ma, M. Song, C. Jing, G. Jiang, Identification of emerging brominated chemicals as the transformation products of tetrabromobisphenol a (TBBPA) derivatives in soil, Environ. Sci. Technol. 51 (2017) 5434-5444.

[10] A. Liu, G. Qu, C. Zhang, Y. Gao, J. Shi, Y. Du, G. Jiang, Identification of two novel brominated contaminants in water samples by ultra-high performance liquid chromatography-orbitrap fusion tribrid mass spectrometer, J. Chromatogr. A 1377 (2015) 92-99.

[11] R.J. Letcher, S. Chu, High-sensitivity method for determination of tetrabromobisphenol-S and tetrabromobisphenol-A derivative flame retardants in Great Lakes herring gull eggs by liquid chromatography-atmospheric pressure photoionization-tandem mass spectrometry, Environ. Sci. Technol. 44 (2010) 8615-8621.

[12] Y. Tian, A. Liu, G. Qu, C. Liu, J. Chen, E. Handberg, J. Shi, H. Chen, G. Jiang, Silver ion post-column derivatization electrospray ionization mass spectrometry for determination of tetrabromobisphenol A derivatives in water samples, RSC Adv. 5 (2015) 17474-17481.

[13] G. Qu, J. Shi, T. Wang, J. Fu, Z. Li, P. Wang, T. Ruan, G. Jiang, Identification of tetrabromobisphenol A diallyl ether as an emerging neurotoxicant in environmental samples by bioassay-directed fractionation and HPLC-APCI-MS/MS, Environ. Sci. Technol. 45 (2011) 5009-5016.

[14] T. Shi, S. Chen, X. Luo, X. Zhang, C. Tang, Y. Luo, Y. Ma, J. Wu, X. Peng, B. Mai, Occurrence of brominated flame retardants other than polybrominated diphenyl ethers in environmental and biota samples from southern China, Chemosphere 74 (2009) 910-916.

[15] M.A. Abdallah, S. Harrad, A. Covaci, Isotope dilution method for determination of polybrominated diphenyl ethers using liquid chromatography coupled to negative ionization atmospheric pressure photoionization tandem mass spectrometry: validation and application to house dust, Anal. Chem. 81 (2009) 7460-7467

[16] G. Qu, A. Liu, T. Wang, C. Zhang, J. Fu, M. Yu, J. Sun, N. Zhu, Z. Li, G. Wei, Y. Du, J. Shi, S. Liu, G. Jiang, Identification of tetrabromobisphenol A allyl ether and tetrabromobisphenol A 2,3-dibromopropyl ether in the ambient environment near a manufacturing site and in mollusks at a coastal region, Environ Sci. Technol. 47 (2013) 4760-4767.

[17] Y. Tian, J. Chen, Y. Ouyang, G. Qu, A. Liu, X. Wang, C. Liu, J. Shi, H. Chen, G. Jiang, Reactive extractive electrospray ionization tandem mass spectrometry for sensitive detection of tetrabromobisphenol A derivatives, Anal. Chim. Acta 814 (2014) 49-54

[18] R. Köppen, R. Becker, C. Jung, C. Piechotta, P.I. Nehls, Investigation of extraction procedures and HPLC-DAD/MS for the determination of the brominated flame retardant tetrabromobisphenol A bis(2,3-dibromopropylether) in environmental samples, Anal Bioanal. Chem. 384 (2006) 1485-1492

[19] J.R. Nyholm, A. Norman, L. Norrgren, P. Haglund, P.L. Andersson, Maternal transfer of brominated flame retardants in zebrafish (Danio rerio), Chemosphere 73 (2008) 203-208.

[20] Y. Zhong, D. Li, Z. Mao, W. Huang, P. a. Peng, P. Chen, J. Mei, Kinetics of tetrabromobisphenol A (TBBPA) reactions with $\mathrm{H} 2 \mathrm{SO} 4, \mathrm{HNO} 3$ and $\mathrm{HCl}$ : implication for hydrometallurgy of electronic wastes, J. Hazard. Mater. 270 (2014) 196-201.

[21] A.R. Reindl, L. Falkowska, Flame retardants at the top of a simulated baltic marine food web-A case study concerning african penguins from the Gdansk Zoo, Arch. Environ. Contam. Toxicol. 68 (2015) 259-264.

[22] F. Hu, L. Pan, M. Xiu, D. Liu, Dietary accumulation of tetrabromobisphenol A and its effects on the scallop Chlamys farreri, Comp. Biochem. Physiol. C: Pharmacol. Toxicol. 167 (2015) 7-14.

[23] F. Peng, G. Ying, B. Yang, Y. Liu, H. Lai, G. Zhou, J. Chen, J. Zhao, Biotransformation of the flame retardant tetrabromobisphenol-A (TBBPA) by freshwater microalgae, Environ. Toxicol. Chem. 33 (2014) 1705-1711.

[24] G.A. Knudsen, L.M. Jacobs, R.K. Kuester, I.G. Sipes, Absorption distribution, metabolism and excretion of intravenously and orally administered tetrabromobisphenol A 2,3-dibromopropyl ether in male Fischer-344 rats, Toxicology 237 (2007) 158-167.

[25] H. Kang, X. Wang, Y. Zhang, J. Wu, H. Wang, Simultaneous extraction of bisphenol A and tetrabromobisphenol A from milk by microwave-assisted ionic liquid microextraction, RSC Adv. 5 (2015) 14631-14636.

[26] B. Kowalski, M. Mazur, The simultaneous determination of six flame retardants in water samples using SPE pre-concentration and UHPLC-UV method, Water Air Soil Pollut. 225 (2014).

[27] A.A. Revista Brasileira de FarmacognosiaPatel, A.A. Amin, A.H. Patwari, M.B. Shah, Validated high performance thin layer chromatography method for simultaneous determination of quercetin and gallic acid in Leea indica, Rev. Bras. Farmacogn. 27 (2017) 50-53.

[28] E. Guzelmeric, P. Ristivojeviíc, I. Vovk, D. s. MilojkoviícOpsenica, E. Yesilada, Quality assessment of marketed chamomile tea products by a validated HPTLC method combined with multivariate analysis, J. Pharm. Biomed. Anal. 132 (2017) 35-45.

[29] P. Dawan, T. Satarpai, P. Tuchinda, J. Shiowatana, A. Siripinyanond, A simple analytical platform based on thin-layer chromatography coupled with paper-based analytical device for determination of total capsaicinoids in chilli samples, Talanta 162 (2017) 460-465

[30] E. Guzelmeric, I. Vovk, E. Yesilada, Development and validation of an HPTLC method for apigenin 7-O-glucoside in chamomile flowers and its application for fingerprint discrimination of chamomile-like materials, J. Pharm. Biomed. Anal. 107 (2015) 108-118.

[31] C.M. Loescher, D.W. Morton, S. Razic, S. Agatonovic-Kustrin, High performance thin layer chromatography (HPTLC) and high performance liquid chromatography (HPLC) for the qualitative and quantitative analysis of Calendula officinalis-advantages and limitations, J. Pharm. Biomed. Anal. 98 (2014) 52-59. 
[32] B. Renger, Z. Végh, K. Ferenczi-Fodor, Validation of thin layer and high performance thin layer chromatographic methods, J. Chromatogr. A 1218 (2011) 2712-2721.

[33] K. Ferenczifodor, B. Renger, Z. Végh, The frustrated reviewer-recurrent failures in manuscripts describing validation of quantitative TLC/HPTLC procedures for analysis of pharmaceuticals, Jpc-J. Planar. Chromatogr. 23 (2010) 173-179.

[34] Y.A. Witos, B. Milz, B. Spangenberg, Two-dimensional thin-layer

chromatography of $17 \alpha$-ethinylestradiol on RP-18 W plate, detected by effect-directed analysis using the YES test, Jpc-J Planar. Chromatogr. 30 (2017) 136-141.
[35] A. Kokotkiewicz, P. Migas, J. Stefanowicz, M. Luczkiewicz, M. Krauze-Baranowska, Densitometric TLC analysis for the control of tropane and steroidal alkaloids in Lycium barbarum, Food Chem. 221 (2017) 535-540.

[36] T. Nakao, E. Akiyama, H. Kakutani, A. Mizuno, O. Aozasa, Y. Akai, S. Ohta, Levels of tetrabromobisphenol A, tribromobisphenol A, dibromobisphenol A, monobromobisphenol A, and bisphenol a in Japanese breast milk, Chem. Res. Toxicol. 28 (2015) 722-728. 